\title{
Virtual Engineering Based Design Integration, Visualization and Validation
}

\section{Hirpa G Lemu*}

Department of Mechanical \& Structural Engineering and Material Technology, University of Stavanger, Norway

Virtual Engineering (VE) is a multidisciplinary field in Computeraided Engineering (CAE) technologies involving interaction of diverse computer-based engineering tools such as computer-aided design (CAD) in geometric modelling, finite element methods (FEM) in analysis and other mechanical and process simulation systems. Within a product's lifecycle, design is the cornerstone and drives the aspiration of simulation-based engineering aimed to create smooth communication among the diverse CAE tools. This demands a collaborative engineering work where $\mathrm{VE}$ and the interface standards play a key role.

Obviously, engineering companies of today are facing a fierce competition in a global market. This race to win the market can be characterized as innovation based because the classical competitive factors should be reconciled with other challenges such as new product brands, ecological, safety and legislation aspects [1]. The solution to this challenge lies in making design engineering data available for other processes used to realize the product where VE can contribute in reducing the product development time, assist engineers in decision making, simplifying generation of alternative design solutions, providing interfaces that allow $3 \mathrm{D}$ model manipulation in a virtual world, making necessary changes and design optimization at low cost, etc. Such capabilities of VE systems are necessary in many industries where testing using physical models is expensive, requires long development time and products are extremely complex [2].

The role of VE in design, as seen from current developments, is quite immense and important specially in integrating diverse engineering activities including easy communication among engineering teams located at different parts of the globe. This is particularly crucial in the context of globalization where companies are operating internationally and sharing data is a necessity.

Mechanical design requires competence and knowledge from diverse fields, for instance, mechanics, solid modelling, creativity, material science, production technology, control techniques, marketing and economics. In addition, the classic design process of design work of a mechanical part or system that is characterized by sequential activities is known to make the time to market very long and does not fit today's production philosophy. It is also a well-established fact that design work is characterized by cross-company collaboration involving intensive exchange of product data, where sequential processes are no longer the options. As a result of the huge rise of computing power and the available commercial and open-source tools [3] the design practice is dynamically changing. For instance, engineers widely use diverse digital tools and operate in multidimensional engineering processes. This has initiated research ideas in collaborative product development where investigating the way engineers currently work and how the newly emerging VE technology and the idea of globalized companies influence the main engineering roles such as design, analysis and design validation [4]. There are clear indications that current research in application of VE technologies using design data has focused on the usability and benefits of the technology by interfacing with standard simulation software such as FEA and multi-body systems [5-8]. As a result, 3D model based computer simulations are now common practices in industry, while research on exploration of the analytical aspects of design process and how the design data is integrated to serve in various stages of the product lifecycle is lacking. Though 3D manipulation capabilities in virtual space have served in creating design visualization easier, making design modification based on real-time virtual simulation can be achieved, particularly in making significant added value for complex applications $[9,10]$, only when virtual design technology is fully utilized.

As stated, the traditional design process that follows the line from design to prototype development, testing prototypes, design analysis and simulation and redesign is time consuming and leads to high production costs $[11,12]$. Rapid prototyping (RP) technology was primarily intended to assist the product development phase of design works by improving design concept visualization and hence reducing the time consumed in developing physical object, in most cases scaled prototypes. This is because RP technologies can develop prototypes for diverse purposes such as design object visualization and verification within a relatively short time. The function or application of such prototypes is highly dependent on the type of technology whose process depends on the material used and other factors.

By using a digital model for testing and design evaluation in a virtual computational environment, the $\mathrm{VE}$ concept is expected to improve some of the shortcomings of current RP technologies [13]. This is because the concept allows getting the physical "feeling" in virtual environment and errors can be detected before high costs are committed. Design iteration on the digital model is cheap and the design optimization is done within shorter time because the number of design iterations using physical models, including those produced by RP technologies is significantly reduced. Most of all, visualization using VE concept is an effective way to create real scenarios that facilitate effective communication of design idea.

It is important to underline here that VE is not an option to completely replace RP technologies in a design validation. While RP technologies still remain the preferred options for direct production of certain customized parts, virtual prototyping as a design idea validation tool is the best option in areas of small-batch production for instance where making physical prototypes or production of patterns and mold is not economical. At the same time, both technologies can supplement each other because virtual prototyping can be used as a means of validation and quality control while RP technologies are used for direct production of parts.

In summary, VE based design lays the foundation of the product

*Corresponding author: Hipra G Lemu, Department of Mechanical and Structura Engineering and Material Technology, University of Stavanger, Norway, Tel: +4751832173; E-mail: hirpa.g.lemu@uis.no

Received February 22, 2014; Accepted February 24, 2014; Published March 12,2014

Citation: Lemu HG (2014) Virtual Engineering Based Design Integration, Visualization and Validation. J Appl Mech Eng 3: e129. doi:10.4172/2168 9873.1000e129

Copyright: @ 2014 Lemu HG, et al. This is an open-access article distributed under the terms of the Creative Commons Attribution License, which permits unrestricted use, distribution, and reproduction in any medium, provided the original author and source are credited. 
data description that can integrate processes involved in a product's lifecycle and contribute in making the manufacturing system intelligent, smart and cost effective. This demands enabling the computer-based technologies to easily communicate to each other with no or less human intervention. Though some of the technologies in this area are sufficiently matured, there still exists significant research to be done in order to achieve real intelligent processes. As indicated earlier, this can be possible if the product data is completely and correctly built in the CAD model and the smooth transfer of this data to other components in the system is enabled through further research.

\section{References}

1. Van der AH, Anthonis J, Bruyne SD, Leuridan J (2013) Virtual engineering at work: the challenges for designing mechatronic products. Eng Comput 29: $389-408$

2. Mandic V, Cosic $P$ (2011) Integrated product and process development in collaborative virtual engineering environment. Technical Gazette 18: 369-378

3. Anagnostopoulos JS (2013) Design of Impulse Hydro Turbines. J Appl Mech Eng 2: e123. doi:10.4172/2168-9873.1000e123.

4. Müller P, Pasch F, Drewinski R, Bedenbender H, Hayaka H, et al. (2012) Study on collaborative product development and digital engineering tools, In: Product Lifecycle Management. Towards Knowledge-Rich Enterprises, IFIP Advances in Information and Communication Technology 388: 389-399.

5. Antonya C, Talaba D (2007) Design evaluation and modification of mechanical systems in virtual environments. Virtual Reality 11: 275-285.

6. Eberhard P, Schiehlen W (2005) Computational dynamics of multibody systems: history, formalisms and applications. Transaction of ASME, J Comput Nonlinear Dyn 1: 3-12.

7. Schiehlen W (2007) Research trends in multibody system dynamics. Multibody Syst Dyn 18: 3-13 .

8. Schiehlen W (1997) Multibody system dynamics: roots and perspectives Multibody Syst Dyn 1: 149-188.

9. Sanchez-Segura MI, Cuadrado Juan J, Moreno AM, Amescua Ad, Angélica de Antonio, et al. (2004) Virtual reality systems estimation vs. traditional systems estimation. J Syst Software 72: 187-194

10. Ritchie J, Simmons J, Holt P, Russell G (2002) Immersive virtual reality as an interactive tool for cable harness design. In: Proceedings of PRASIC 2002product design, University of Transilvania, Brasov, Romania, 3: 249-255

11. Pham DT, Gault RS (1998) A comparison of rapid prototyping technologies. Int J Mach Tools Manuf 38:1257-1287.

12. Choi SH, Chan AMM (2004) A virtual prototyping system for rapid product development. Computer Aided Design 36: 401-412.

13. Lemu HG (2013) Study of the Role of Virtual Engineering Technologies in Design. In: Proc. of Int. Workshop of Advanced Manufacturing and Automation (IWAMA 2013), eds. K. Wang, J.O. Strandhagen and D. Tu, Tapir Academic Press nr. 4:59-69. 